\title{
Characteristics of Energy Dissipation in the Process of Rock Damage under Cyclic Impact
}

\author{
N. $\mathrm{Hu}^{1}$, C. Li ${ }^{1 *}$, E. Boda ${ }^{2}$, Y. Xiao ${ }^{1}$, and Z. Hou ${ }^{1}$ \\ ${ }^{1}$ School of Civil and Resource Engineering, University of Science and Technology Beijing, Beijing 100083, China \\ ${ }^{2}$ KC Engineering, Gasabo district, Kigali, K324, Rwanda
}

Received 16 October 2020; Accepted 2 January 2021

\begin{abstract}
Energy absorption and dissipation are mainly involved in the rock breaking process which is affected by many factors, such as impact strength, number of cycles, and rock material characteristics. In this study, a novel method was proposed to reveal the mechanical properties and energy dissipation law of surrounding rock under the cyclic impact. A split Hopkinson pressure bar (SHPB) test device was used to obtain the energy dissipation characteristics of granite samples. The stress-strain evolution process was compared with the energy dissipation process to analyze the characteristics of incident energy, transmitted energy, and reflected energy in each stage of the impact process. A relationship between impact strength and energy dissipation was established. Results demonstrate that under the impact load, the rock is primarily an axial tensile failure, and the dissipated energy is mainly in the form of surface energy in crack propagation. With the increase in impact, the number of active cracks, the ratio of incident energy to strain energy, and the ratio of reflected energy all increase, whereas the ratio of transmitted energy decreases. The larger the impact load, the larger the proportion of strain energy absorption, and the average value increases from $28.49 \%$ to $30.51 \%$. The proportion of single strain energy absorption under cyclic impact conditions is far less than $40.57 \%$ of single impact failure. This study contributes to the optimization design of blasting engineering and the production safety improvement in metal mining.
\end{abstract}

Keywords: Cyclic shock, Energy dissipation, Rock, Strain energy

\section{Introduction}

In the mining process of metal mines, the multiple impact loads with different strengths are often accompanied by the blasting process [1]. The surrounding rock in the middle and far area around the explosion point will appear different degrees of damage cracks under the action of multiple impact loads, and these cracks will start to expand, connect, and even cause the surrounding rock instability [2]. The failure process of rock is affected by many factors, and the state information of surrounding rock is relatively difficult to measure. Therefore, the stability of surrounding rock in underground blasting mining should be extensively investigated. At present, cyclic impact load has been examined using several research directions. The first stream of research focuses on the mechanical properties in the process of impact, such as impact strength and strain rate. The second stream has used diverse material response characteristics under the impact, such as weakly weathered sandstone, cemented backfill, and other materials with large mechanical differences. The last stream has considered energy evolution in the process of impact, including energy absorption and transmission.

However, the damage process of rock is complex. The damage process of rock is affected by many external factors, such as temperature, stress environment, and moisture content, and characterized by phases. Thus, its response to load is varied in different damage stages.

\footnotetext{
*E-mail address: LICHUSTB@126.com

ISSN: 1791-2377 @ 2021 School of Science, IHU. All rights reserved. doi:10.25103/jestr.141.07
}

On this basis, the response characteristics of different rock materials under cyclic impact load have received considerable scholarly attention [3-5]. However, existing literature on energy dissipation is relatively little. In particular, studies on the characteristics of energy absorption, reflection, and transmission corresponding to the damage process of rock remain inadequate. Moreover, the lack of relevant work does not allow for combining the existing damage mechanics theory with the test results.

Therefore, in this study, a split Hopkinson pressure bar (SHPB) device with a large diameter is employed to carry out the cyclic impact of different strengths on the collected rock samples. The obtained stress-strain characteristics and energy evolution characteristics can guide further studies on rock impact resistance.

\section{State of the Art}

At present, the cyclic impact process of rocks has been extensively investigated. Yang et al. [6] carried out a series of one-dimensional combined dynamic and static loading tests on the mechanical properties, permeability, wave velocity, and acoustic emission of the sample using the proposed static, dynamic, and static loading mode. However, they focused on the coordination of dynamic and static loads and failed to explain the role of dynamic load in the loading process. Lu et al. [7] examined the influence of different strain rates and loading rates on mechanical parameters, such as impact strength, yield strength, and elastic modulus of coal and rock. They found that the change in the above mechanical parameters was only an indirect reflection of 
internal microstructure damage and microcrack propagation evolution of coal and rock. Zhao et al. [8] reflected the change law of coal and rock internal microstructure under impact load by observing the microcrack propagation and evolution law on coal and rock surfaces. They also qualitatively described the damage process of coal and rock internal microstructure. Given the different emphasis of the test, the energy evolution failed to correspond to the damage process. Li et al. [9] used SHPB, NMR, and SEM to study coal and rock and analyzed the evolution characteristics of pores and cracks under different impact loads. They only considered crack morphology evolution, which was not closely related to the mechanical characteristics in engineering. Shu et al. [10] tested heat-treated granite under a cyclic impact load test and obtained the relationship between rock energy and failure mode and temperature. They focused on the influence of temperature on the damage process and paid relatively little attention to the energy dissipation process. $\mathrm{Yu}$ et al. [11] revealed the influence of confining pressure on rock stress-strain, damage factor, and other physical quantities by setting different confining pressures on sandstone. Although they obtained the relationship between strain rate and damage degree, they did not describe the damage in the process in detail and the degree evolution. Wang et al. [12] studied the energy consumption characteristics of weathered red sandstone and analyzed its change characteristics under different axial pressures and impact loads. The selected materials had low strength and could not fully reflect the impact resistance of the rock. Li et al. [13] used a pendulum-driven separate SHPB device to perform repeated impact compression tests on green sandstone. They studied the acoustic properties, dissipated energy, deformation properties, and microstructure evolution of the material, but the impact load used was relatively small.

Braunagel MJ [14] studied the dynamic compressive strength and failure mechanism of granite under cyclic loading using the SHPB test device. The compressive strength of the specimen would decrease under cyclic loading. The strength of the rock increased with the increase of the loading speed. Under the extremely fast loading speed, the failure of the rock changed from a simple fracture to a broken state, but a detailed description of its breaking process was not available. Hokka et al. [15] carried out an experimental study on the mechanical properties of granite. The results showed that the strain rate effect was more obvious at low confining pressure than at high confining pressure. Lundberg et al. [16] examined the rock failure mechanism. They found that under the impact load, the crack propagated along the axial direction. With the increase of dynamic load, the fracture degree of the crack also increased. After the failure, the rock sample was in the form of symmetric cone failure. However, the cause of the failure form could not be explained. Raynaud et al. [17] used X-ray CT scanning technology to scan internal cracks without damaging the rock samples. They observed the static deformation and fracture of rock samples under a threedimensional stress state. They did not conduct a mechanical analysis of the fracture process. Kawakata et al. [18] established three-dimensional CT images on the basis of the CT scanning data of rock sample end face, which directly showed the distribution and morphology of cracks. Yet, their investigation on the development process and causes of cracks was insufficient. Alam MS et al. [19] studied the dynamic characteristics of sandstone affected by impact strain rate. They found that deformation modulus, impact strength, and fracture energy increased with the increase of impact strain rate. The evolution process of energy was disregarded. Kleplaczko et al. [20] studied the mechanical properties of coal and rock under quasi-static and impact loads. They analyzed the elastic characteristics of coal and rock under the impact, but the coal rock material brittleness was small, which could not reflect its impact resistance. Shalev et al. [21] analyzed the relationship between bulk strain, bulk modulus, and hysteresis effect and amplitude during loading and unloading, but the loading rate used in the test was low.

The above studies focused on the mechanical law of the rock failure process under impact load or the influence of different external environments on rock fracture characteristics. Consequently, the energy dissipation law of rock under cyclic load remains underexplored. In the current study, an SHPB device is employed to carry out the cyclic impact test on the collected granite specimens under different strengths. The mechanical properties and evolution law of the impact resistance of granite are analyzed, and the process of energy transmission and dissipation in the process is studied. The development process of microcracks is analyzed using the damage mechanics principle. It has a reference significance for the stability analysis of surrounding rock in mineral mining.

The remainder of this study is organized as follows. The third section describes the specimen preparation and test process of the Hopkinson test. In the fourth section, a correlation analysis is conducted on the energy dissipation and crack evolution process of granite specimen in the process of cyclic impact. The analysis results show the energy dissipation law of each stage. The last section summarizes this study and provides relevant conclusions.

\section{Methodology}

\subsection{Test sample}

The samples used in this test are granite with high brittleness. The samples without obvious joints, cracks, and other defects are selected for cutting and grinding. Following the recommendations of the international society of rock mechanics on the length diameter ratio of rock samples under impact load, specimens with a diameter of $50 \mathrm{~mm}$ and a thickness of $25 \mathrm{~mm}$ are made. A wave velocity test is carried out before the test to reduce the discreteness of the test results. Finally, the specimens with similar wave velocities are selected for the next test.

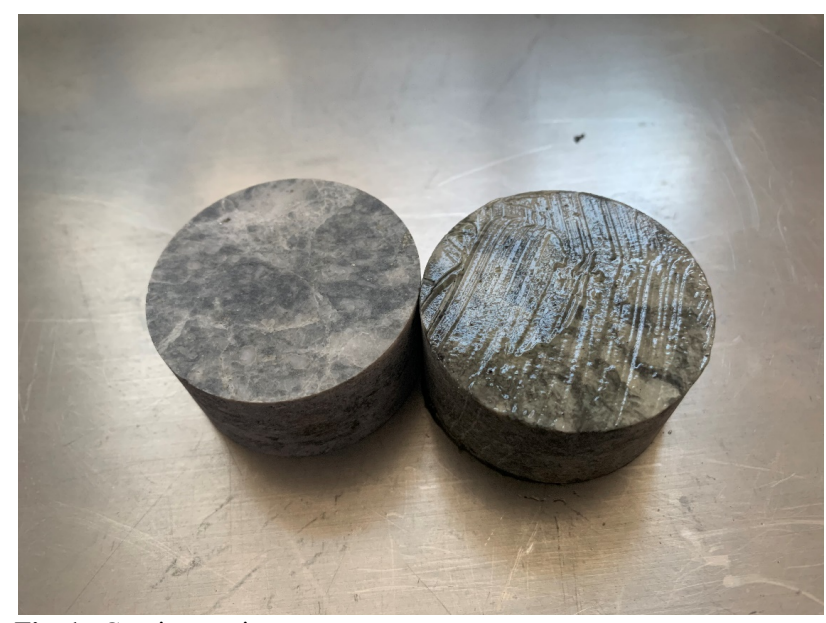

Fig. 1. Granite specimen 


\subsection{Test equipment}

Using the SHPB device to simulate the cyclic impact load, the SHPB system mainly includes three parts: power drive system, pressure bar system, and data receiving and acquisition system. The length of the incident and transmission rods is $2 \mathrm{~m}$. The Poisson's ratio is 0.3 , the elastic modulus is $210 \mathrm{GPa}$, the density is $7800 \mathrm{Kg} / \mathrm{m}^{3}$, and the one-dimensional stress wave velocity is $5190 \mathrm{~m} / \mathrm{s}$. The rock sample is placed between the incident rod and the transmission rod, and the projectile is pressurized by air to accelerate the impact of the incident rod. Subsequently, the impact load is applied to the rock sample to realize the impact process.

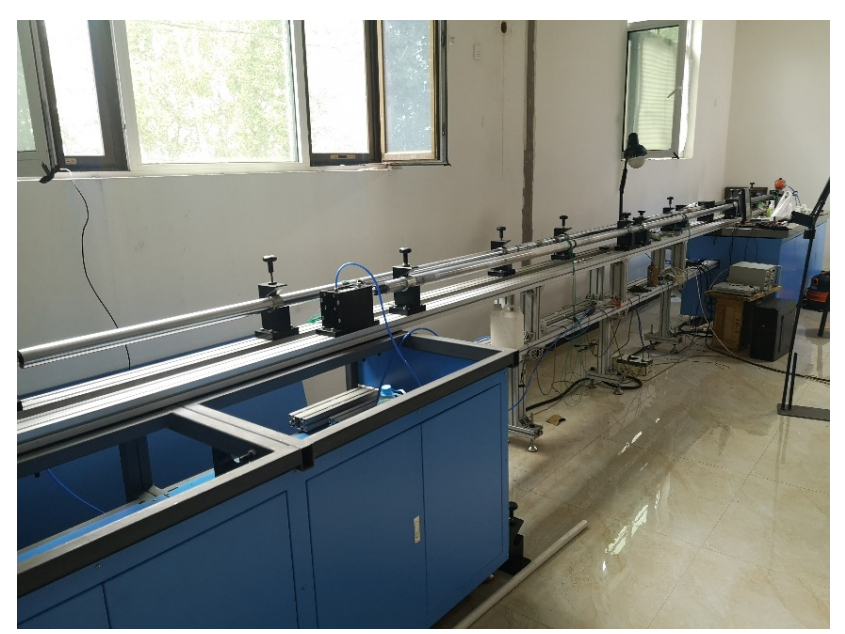

Fig. 2. An SHPB test device

\subsection{Test principle}

The basic principle of the SHPB experiment is based on two basic assumptions of one-dimensional stress assumption and stress uniformity assumption, namely, one-dimensional assumption (also known as a plane assumption) and stress uniformity assumption. The one-dimensional assumption is that each cross-section of the elastic rod is always in a plane state during stress wave propagation in the slender rod. The stress uniformity assumption is that the stress wave is repeated two to three times in the specimen, and the stress in the specimen remains equal.

The stress and strain of the specimen are calculated using the three-wave formula:

$$
\begin{aligned}
& \delta(t)=\frac{A E}{2 A_{0}}\left[\varepsilon_{i}(t)+\varepsilon_{\mathrm{r}}(t)+\varepsilon_{\mathrm{t}}(t)\right] \\
& \varepsilon(t)=\frac{c}{l} \int_{0}^{t}\left[\varepsilon_{i}(t)-\varepsilon_{\mathrm{r}}(t)-\varepsilon_{\mathrm{t}}(t)\right] \mathrm{d} t
\end{aligned}
$$

The energy of the SHPB stress wave is obtained using equation (3):

$$
W=\frac{A}{\rho c} \int_{0}^{t} \delta^{2}(t) \mathrm{d} t
$$

where $A_{0}$ and $l$ are the cross-sectional area and length of the specimen. $A$ is the cross-sectional area of the input and output rods, $\rho$ is the rod density, and $c$ is the onedimensional stress wave velocity. $t$ is the time, $\varepsilon_{i}$ is the incident wave strain, $\varepsilon_{\mathrm{r}}$ is the reflected wave strain, and $\varepsilon_{\mathrm{t}}$ is the transmission wave strain.

The dissipated energy $W_{\mathrm{d}}$ can be expressed as:

$W_{\mathrm{d}}=W_{\mathrm{i}}-\left(W_{\mathrm{r}}+W_{\mathrm{t}}\right)$

where $W_{\mathrm{d}}$ is the dissipative energy, $W_{\mathrm{i}}$ is the incident energy, $W_{\mathrm{r}}$ is the reflected energy, and $W_{\mathrm{t}}$ is the transmitted energy.

\section{Result Analysis and Discussion}

\subsection{Mechanical characteristics and energy dissipation process of the specimen}

Under the impact of different accelerating air pressure, the damage of the specimen is shown in Fig. 3 Among them, (a), (b) and (c) are the results of damage under cyclic impact loading, and the acceleration pressure is $0.09 \mathrm{MPa}, 0.12 \mathrm{MPa}$ and $0.16 \mathrm{MPa}$ respectively; (d) is the single impact failure test, and the acceleration pressure is $0.20 \mathrm{MPa}$.

Under the action of low-speed cyclic impact load, the damage of the rock is mainly the tensile fracture along the axial direction, as shown in Figure (a) and Figure (b). With the increase of the accelerating air pressure, the damage of the rock is intensified, and the proportion of wedge-shaped fragments increases, as shown in Figures (c) and (d), indicating that the proportion of shear-type oblique cracks increases with the increase of impact load.

The typical stress-strain curve in the cyclic impact process is shown in Fig. 4 The process is mainly divided into elastic deformation stage, plastic deformation stage and stable crack growth stage after reaching the peak value. When the axial stress in the specimen reaches a certain value, the normal tensile stress will be formed in the original damaged part of the specimen, resulting in the axial tensile failure of the specimen. The cracking process of the crack makes the specimen form normal expansion, the stress does not increase, but the stress increases steadily. After the stress wave inside the specimen decays, the stress decays rapidly and the crack closes.

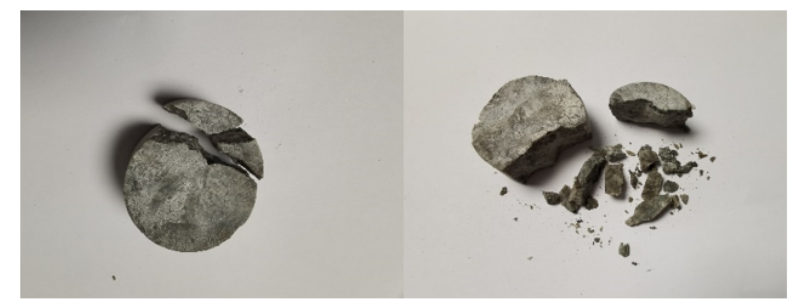

(a)

(b)

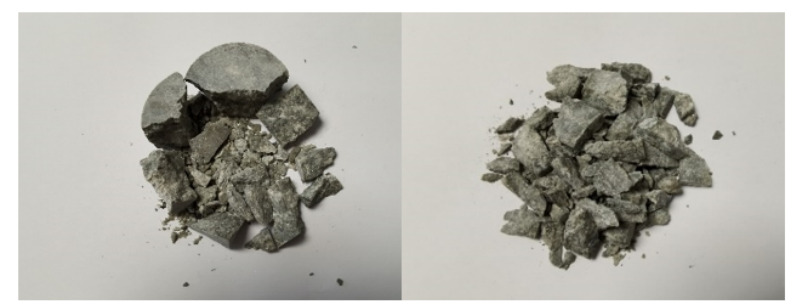

(c)

(d)

Fig. 3. Rock failure under different working conditions 


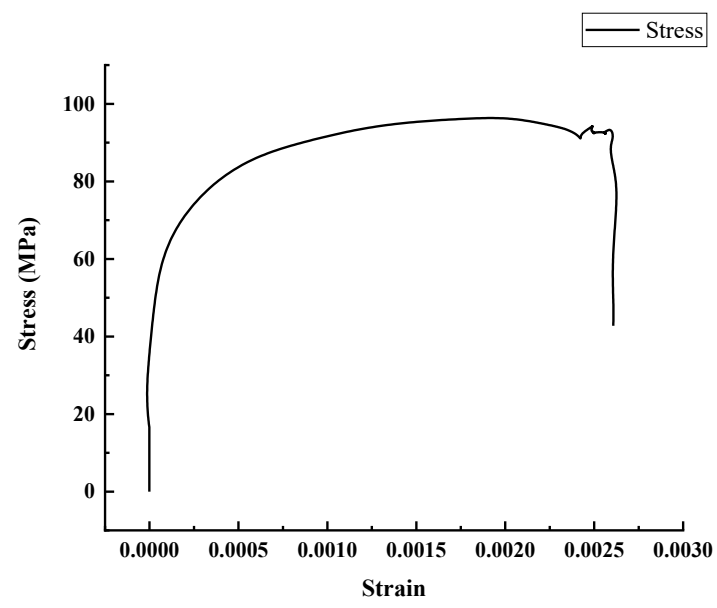

Fig. 4. Typical stress-strain curves

During the impact process, the evolution of absorbed energy is closely related to the evolution of stress. Fig. 5 shows the time curve of stress-strain energy absorption rate. In the elastic stage, the absorbed energy is almost zero; with the increase of stress, the specimen produces plastic deformation, and part of the energy carried by the stress wave is converted into the internal energy generated by plastic deformation; when the stress reaches the maximum, the crack is stable and the conversion rate of strain energy remains unchanged, and the incident energy is converted into the surface energy of crack cracking.

\subsection{Transformation characteristics of strain energy}

In the process of impact loading, the stress wave conducts and vibrates in the specimen, which causes the stress concentration in the original damaged part of the specimen and forms cracks. The incident energy is transformed into surface energy during the crack propagation process and dissipated in the specimen. Under the same impact load, the change trend of strain energy absorption rate is almost the same. With the development of cyclic impact, the strain energy gradually accumulates, and the number of cracks in the specimen increases and expands. According to the theory of damage mechanics, the crack propagation can be divided into the compaction stage of the original crack and the micro void, the formation of the damage nucleus stage of the new crack, and the propagation and penetration stage of the crack.

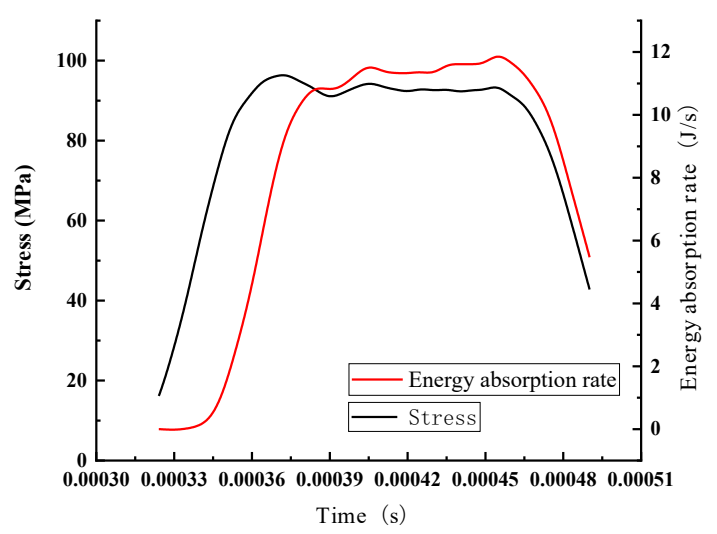

Fig. 5. Stress-strain energy absorption rate curve

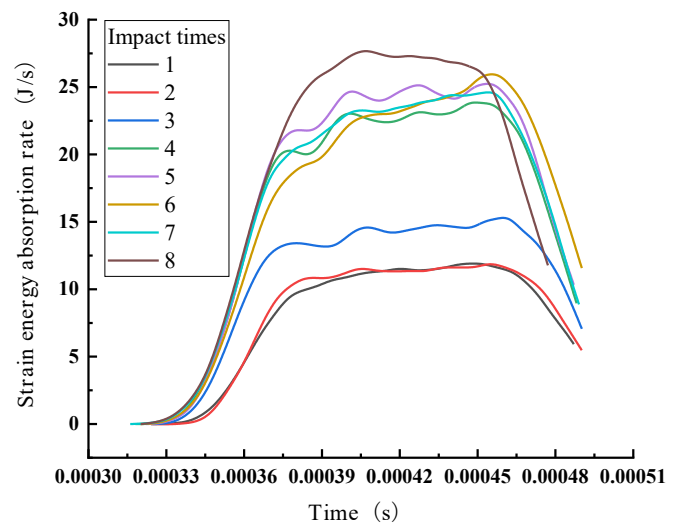

Fig. 6. Strain energy absorption curve under the condition of $0.09 \mathrm{MPa}$ accelerating pressure

The strain energy absorption rate of A1 specimen under 0.09Mpa acceleration pressure is shown in Fig. 6 Due to the small impact load on the specimen, the internal damage of the specimen is not obvious in the previous impact process, and the stage of low energy absorption rate lasts for a long time, which indicates that the energy absorption rate of the initial crack compaction and crack nucleation stage is low. With the accumulation of damage, the number of active cracks increases, the cracks expand greatly, and the maximum energy absorption rate increases and maintains at a stable level, as shown in the 4th to 7 th impact process in Fig. 6 The results show that the internal crack of the specimen is expanding steadily, and the energy absorption rate is high in the expanding stage, and the impact energy is rapidly converted into the surface energy of the crack. During the third to seventh impact, the energy absorption rate fluctuates obviously, which indicates that the crack propagation is not uniform during the impact process, and large-scale crack propagation or concentrated crack propagation will occur, resulting in the increase of energy absorption rate. After that, the crack propagation will cause the release of local energy and stress, resulting in the decrease of energy absorption rate, and finally the energy absorption rate is stable. In the last impact process, the crack penetrates in a large scale, resulting in the failure of the specimen, so the energy absorption rate of the specimen reaches a peak value.

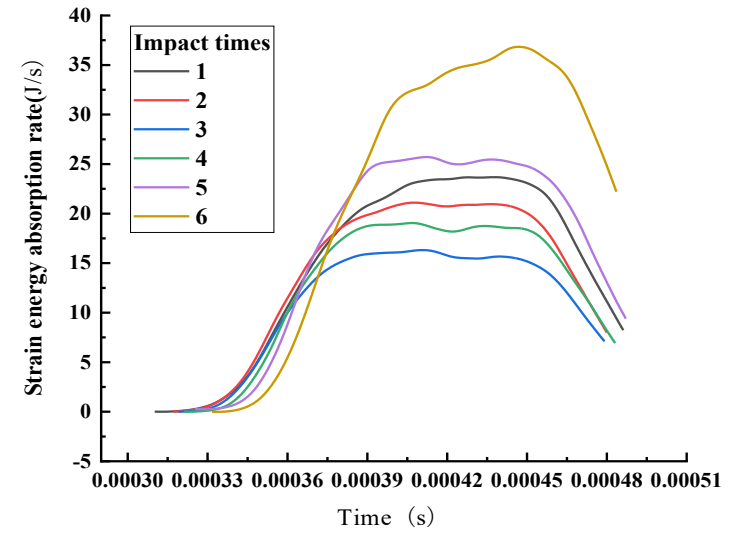

Fig. 7. Strain energy absorption curve under $0.12 \mathrm{MPa}$ accelerated air pressure 
The energy absorption rate curve of B1 specimen under $0.12 \mathrm{MPa}$ acceleration pressure is shown in Figure 7. Due to the increase of impact load, the compaction, nucleation and propagation of the original crack are not obvious. The results show that the maximum strain energy absorption rate first decreases and then increases. The first three impact processes are mainly affected by the crack compaction and the nucleation stage of the original crack, so the energy absorption rate gradually decreases in the first three impact processes. With the weakening of compaction, the internal cracks begin to expand and the energy absorption rate increases.

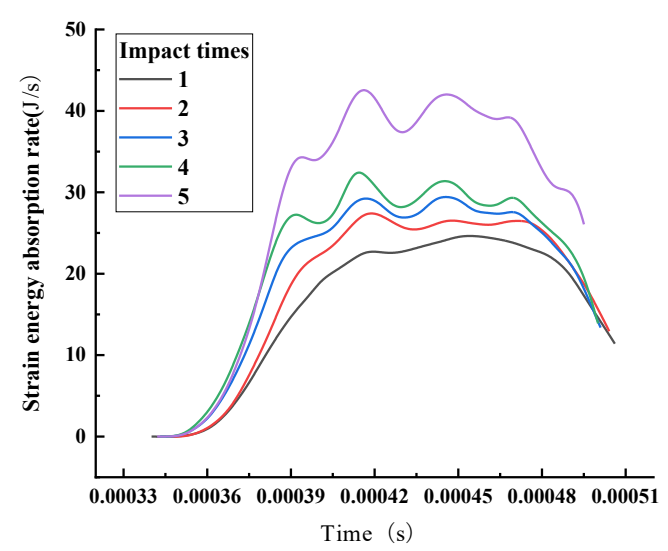

Fig. 8. Strain energy absorption curve under $0.16 \mathrm{MPa}$ accelerated air pressure

The strain energy absorption rate of $\mathrm{C} 1$ specimen under $0.16 \mathrm{MPa}$ acceleration pressure is shown in Fig. 8. With the impact process, the trend of strain energy change rate is similar to that of $\mathrm{A} 1$, and the strain energy absorption rate increases gradually, but the minimum value of peak absorption rate is about $25 \mathrm{~J} / \mathrm{s}$, which is significantly higher than that of A1. The results show that the compaction response of rock material is not obvious under the action of large impact load, and the crack propagation is obvious at the initial stage under the action of large impact load. There is obvious fluctuation in the peak stage of strain energy absorption rate, which indicates that the larger impact load in this stage leads to the larger scale crack expansion and penetration.

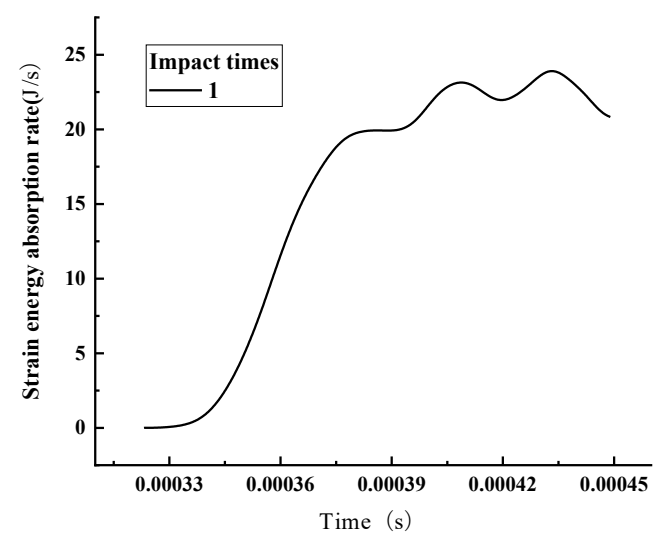

Fig. 9. Curve of strain energy absorption under 0.20MPa accelerated air pressure
Fig. 9 shows the strain energy absorption rate of D1 specimen under $0.2 \mathrm{MPa}$ acceleration pressure. It can be seen that the maximum absorption rate is $25 \mathrm{~J} / \mathrm{s}$, which is slightly higher than the first impact of the previous three tests, but it is not obvious. This is mainly due to the failure of the specimen due to the rapid penetration of the micro cracks along the weak plane instead of fully expanding under the large impact load.

\subsection{Evolution law of strain energy, transmitted energy and reflected energy}

In the process of cyclic impact loading, due to the relatively low acceleration pressure, the incident energy transmitted by the bullet in the process of impact on the incident bar is unstable. Therefore, comparing the proportion of strain energy, reflection energy and transmission energy in the incident energy can further improve the rationality of the data. The proportion of strain energy, reflection energy, transmission energy, incident energy and three kinds of energy is shown in Table 1.

The energy absorption rate is closely related to the strength of impact load and the internal damage of rock. The results show that the impact load of A1 specimen is small, the internal crack size is small, and its energy absorption rate is relatively low; and with the impact, the overall absorption rate shows an increasing trend, from the lowest $21.62 \%$ to $40.571 \%$, and the average energy absorption rate is $28.49 \%$. The results show that the energy absorption rate of B1 sample first decreases and then increases. The results show that the rock material can also absorb the impact energy in the initial compaction process; the damage degree of the specimen in the later stage is accumulating, and the energy absorption rate is gradually increasing, and the average energy absorption rate is $29.51 \%$. The results show that the strain energy absorption rate of $\mathrm{C} 1$ specimen increases steadily under large impact load, which indicates that the crack propagation rate is relatively stable under large impact load, and the average energy absorption rate is $30.51 \%$. The proportion of strain energy of D1 specimen under single impact load is significantly higher than that under cyclic impact load, which is $40.57 \%$.

Compared with the impact load of different strength, the lower impact load is difficult to cause the effective compaction inside the material. In the damage process of the specimen, small-size cracks are mainly formed. With the impact, the cracks form local penetration, resulting in local longitudinal cracking of the specimen. When the impact load is large, the compaction and crack propagation proceed simultaneously. Under the impact of medium strength, the effect of compaction is more prominent.

Compared with the impact load of different strength, the lower impact load is difficult to cause the effective compaction inside the material. In the damage process of the specimen, small-size cracks are mainly formed. With the impact, the cracks form local penetration, resulting in local longitudinal cracking of the specimen. When the impact load is large, the compaction and crack propagation proceed simultaneously. Under the impact of medium strength, the effect of compaction is more prominent. 
Table 1. Evolution law of strain energy, transmitted energy and reflected energy

\begin{tabular}{|c|c|c|c|c|c|c|c|c|}
\hline $\begin{array}{l}\text { Accelerating air } \\
\text { pressure(MPa) }\end{array}$ & $\begin{array}{l}\text { Number } \\
\text { of impacts }\end{array}$ & $\begin{array}{l}\text { Strain } \\
\text { energy }(J)\end{array}$ & $\begin{array}{l}\text { Strain } \\
\text { energy ratio }\end{array}$ & $\begin{array}{l}\text { Reflective } \\
\text { energy }(J)\end{array}$ & $\begin{array}{l}\text { Reflective } \\
\text { energy ratio }\end{array}$ & $\begin{array}{c}\text { Transmission } \\
\text { energy }(J)\end{array}$ & $\begin{array}{l}\text { Transmission } \\
\text { energy ratio }\end{array}$ & $\begin{array}{l}\text { Incident } \\
\text { energy }(J)\end{array}$ \\
\hline 0.1 & $\begin{array}{l}1 \\
2 \\
3 \\
4 \\
5 \\
6 \\
7 \\
8 \\
\end{array}$ & $\begin{array}{l}26.78 \\
27.77 \\
30.74 \\
37.79 \\
41.00 \\
40.83 \\
38.28 \\
42.29 \\
\end{array}$ & $\begin{array}{l}22.95 \% \\
21.62 \% \\
25.64 \% \\
30.79 \% \\
32.63 \% \\
30.92 \% \\
29.37 \% \\
33.97 \% \\
\end{array}$ & $\begin{array}{l}1.22 \\
1.35 \\
1.22 \\
2.56 \\
2.69 \\
2.45 \\
2.47 \\
3.49 \\
\end{array}$ & $\begin{array}{l}1.05 \% \\
1.06 \% \\
1.02 \% \\
2.09 \% \\
2.14 \% \\
1.86 \% \\
1.90 \% \\
2.81 \% \\
\end{array}$ & $\begin{array}{l}88.71 \\
99.34 \\
87.91 \\
82.40 \\
81.96 \\
88.76 \\
89.58 \\
78.72 \\
\end{array}$ & $\begin{array}{l}76.00 \% \\
77.33 \% \\
73.33 \% \\
67.12 \% \\
65.23 \% \\
67.22 \% \\
68.73 \% \\
63.22 \% \\
\end{array}$ & $\begin{array}{l}116.73 \\
128.47 \\
119.89 \\
122.76 \\
125.66 \\
132.06 \\
130.34 \\
124.51 \\
\end{array}$ \\
\hline 0.12 & $\begin{array}{l}1 \\
2 \\
3 \\
4 \\
5 \\
6\end{array}$ & $\begin{array}{l}52.31 \\
46.70 \\
36.65 \\
42.62 \\
51.00 \\
68.09 \\
\end{array}$ & $\begin{array}{l}30.08 \% \\
27.72 \% \\
23.20 \% \\
26.06 \% \\
30.77 \% \\
39.25 \% \\
\end{array}$ & $\begin{array}{l}4.23 \\
2.77 \\
1.63 \\
2.46 \\
3.99 \\
7.50 \\
\end{array}$ & $\begin{array}{l}2.43 \% \\
1.65 \% \\
1.03 \% \\
1.51 \% \\
2.41 \% \\
4.32 \% \\
\end{array}$ & $\begin{array}{c}117.36 \\
118.98 \\
119.72 \\
118.48 \\
110.78 \\
97.91 \\
\end{array}$ & $\begin{array}{l}67.48 \% \\
70.63 \% \\
75.77 \% \\
72.43 \% \\
66.83 \% \\
56.43 \% \\
\end{array}$ & $\begin{array}{l}173.91 \\
168.46 \\
158.01 \\
163.56 \\
165.77 \\
173.50\end{array}$ \\
\hline 0.16 & $\begin{array}{l}1 \\
2 \\
3 \\
4 \\
5\end{array}$ & $\begin{array}{l}56.52 \\
60.34 \\
65.01 \\
70.15 \\
76.44\end{array}$ & $\begin{array}{c}27.87 \% \\
29.24 \% \\
30.02 \% \\
30.310 \% \\
35.121 \%\end{array}$ & $\begin{array}{l}3.54 \\
3.86 \\
3.92 \\
4.22 \\
6.87\end{array}$ & $\begin{array}{l}1.75 \% \\
1.87 \% \\
1.81 \% \\
1.83 \% \\
3.16 \%\end{array}$ & $\begin{array}{l}142.67 \\
142.10 \\
147.64 \\
157.06 \\
134.33\end{array}$ & $\begin{array}{l}70.37 \% \\
68.88 \% \\
68.17 \% \\
67.86 \% \\
61.72 \%\end{array}$ & $\begin{array}{l}202.74 \\
206.31 \\
216.57 \\
231.44 \\
217.66\end{array}$ \\
\hline 0.2 & 1 & 39.11 & $40.57 \%$ & 8.72 & $9.05 \%$ & 48.57 & $50.38 \%$ & 96.42 \\
\hline
\end{tabular}

During the conduction process, the stress wave will form reflection at the interface of the material and be absorbed in the damage process of the material. Therefore, the proportion and change of the strain energy, reflection energy and transmission energy can well reflect the internal damage process of the specimen. The variation of strain energy ratio with the increase of impact times is shown in Figure 10-12. Under different impact loads, the proportion of transmitted energy is the highest, the proportion of absorbed energy is the second, the proportion of reflected energy is generally low, and the change range is small.

In the process of cyclic impact, the energy absorption rate of A1 specimen shows an increasing trend, and the initial value is small, which indicates that under the impact of low strength, the energy absorption is less in the compaction and nucleation stage of crack. With the stable growth of crack, the energy absorption point increases and the absorption proportion increases. The curve of B1 specimen shows obvious V-shape. The analysis shows that with the increase of impact load, the compaction and nucleation stages of cracks coincide to a certain extent, resulting in a large proportion of energy absorption, and the two processes weaken with the impact. After that, the crack growth process absorbed a lot of energy, so the curve tended to rise. The load of $\mathrm{C} 1$ specimen is larger than the stress threshold of crack propagation. The internal crack begins to expand in the initial impact and develops steadily in the subsequent impact, so the curve trend increases slowly. The total energy absorbed by D1 specimen in the single impact failure process is $39.11 \mathrm{~J}$, which is far less than the previous three tests. However, the proportion of energy absorption is higher than that of other samples, which indicates that the process of crack penetration is conducive to energy absorption.

The reflection and transmission of energy are closely related to the effective reflection area on the stress wave propagation path. The reflection energy of A1 is $1.02 \%$ and $2.81 \%$ respectively. The lowest reflection energy ratio of $\mathrm{C} 1$ specimen is $1.75 \%$, and the reflection energy ratio fluctuates little before fracture. The maximum reflection energy ratio appears in the last impact process, which is $3.76 \%$. The proportion of reflected energy of B1 specimen first decreases and then increases, which indicates that the early compaction makes the cracks in the material close, resulting in the reduction of normal damage interface area, thus improving the transmission effect of stress wave, that is, reducing the normal damage degree, which has a certain "healing" effect on the material damage. The energy reflectivity of D1 specimen is obviously higher than that of cyclic impact, because the longitudinal crack and transverse crack develop simultaneously under high velocity impact, and the failure mode is X-mode shear failure. The change trend of the proportion of the transmitted energy and the proportion of the reflected energy is roughly opposite, which can also be proved from another point of view.

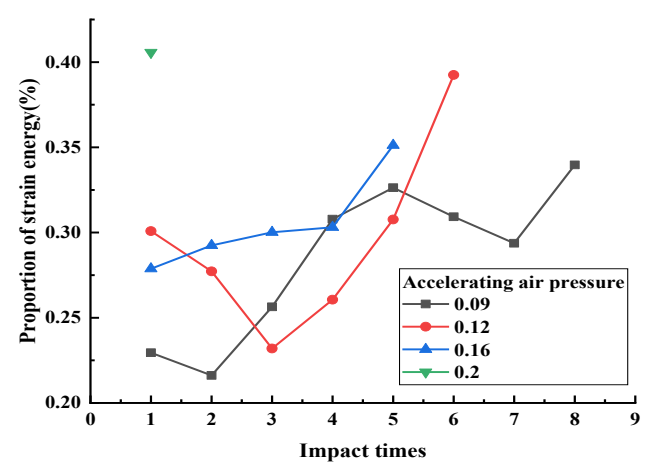

Fig. 10. Ratio of strain energy under different working conditions

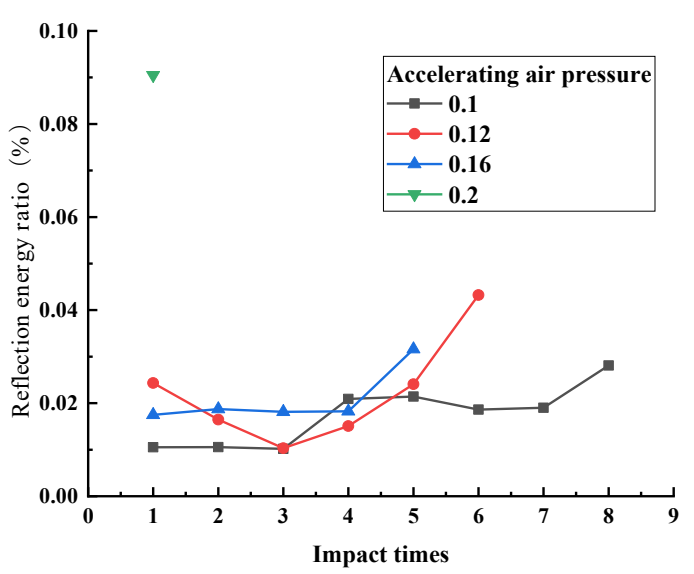

Fig. 11. Reflected energy ratio under different working conditions 


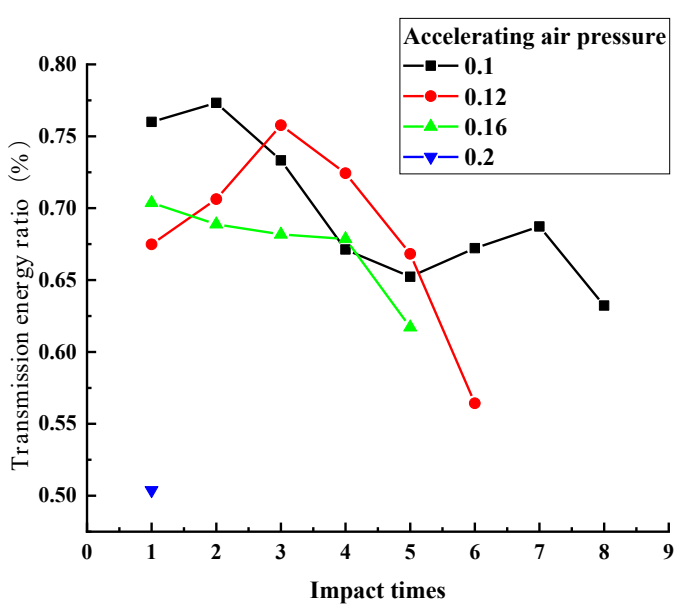

Fig. 12. Transmission energy ratio under different working conditions

\section{Conclusions}

In order to explore the damage process of rock materials in cyclic impact and reveal the relationship between energy dissipation and mechanical evolution, a SHPB test device was used on the basis of damage mechanics theory to carry out impact tests on granite specimens with different strengths. The energy evolution data was analyzed in the process of stress wave transmission. The following conclusions could be drawn:

(1) Under the impact load, the granite is primarily an axial tensile failure. With the increase of impact load, the fracture degree of the specimen increases.
(2) Energy dissipation mainly exists in the form of surface energy during crack propagation. As the impact increases, the number of activated cracks, the proportion of incident energy converted into strain energy, and the proportion of reflected energy all increase, whereas the proportion of transmitted energy decreases.

(3) The higher the impact load, the higher the conversion rate of strain energy. The single strain energy absorption rate under cyclic impact is much lower than that under the single impact. However, the total energy absorbed in the process of cyclic impact load is greater than that of a single impact load.

In this study, the indoor test and theoretical study are combined. An analysis method is proposed and verified by the energy evolution law in the damage process of rock and stone and the damage process of rock in damage mechanics theory. The damage process established is closer to the field practice and improves the understanding of the damage process of rock under the cyclic impact. Given the limitation of indoor test on material size, in the future study, combining the field test data with this model and modifying it will further improve the accuracy and safety of blasting mining.

\section{Acknowledgements}

This work was supported by the National key technologies Research and Development program (2018YFC0808402) and the Fundamental Research Funds for the Central Universities (FRF-TP-20-004A2).

This is an Open Access article distributed under the terms of the Creative Commons Attribution License.

\section{References}

1. Jia, L., Xie, Y., Li,S., "Numerical simulation for impact of blasting vibration on nearby tunnel lining safety". Journal of Vibration and Shock, 34(11), 2015, pp. 173-177.

2. Jin, J., Li, X., Zhong, H., "Study of dynamic mechanical characteristic of sandstone subjected to three-dimensional coupled static-cyclic impact loadings". Chinese Journal of Rock Mechanics and Engineering, 32(7), 2013, pp. 1358-1372.

3. Liu, J., Xu, J., Lv X., Zhao, D., Leng, B., "Experimental study on dynamic mechanical properties of amphibolites under impact compressive loading". Chinese Journal of Rock Mechanics and Engineering, 28(10), 2009, pp. 209-217.

4. Li, X., Li, H., Liu, K., Zhang, Q., Zou, F., Huang, L., Zhao, J., "Dynamic properties and fracture characteristics of rocks subject to impact loading". Chinese Journal of Rock Mechanics and Engineering, 36(10), 2017, pp. 2393-2405.

5. Gan, D., Liu, Z., Li Z., Gao, F., Ren, H., "Broken energy dissipation characteristics of magnetite under impact loads". Chinese Journal of Rock Mechanics and Engineering, (Suppl1), 2018, pp. 3500-3506.

6. Yang, F., Hu, D., Zhou, H., Lu, J., Zhang, F., "Study on physical and mechanical properties of granite after dynamic disturbance". Chinese Journal of Rock Mechanics and Engineering, 37(6), 2018, pp. 14591467.

7. Lu, Z., Wang, Z., "Triaxial tests on dynamic properties of granite under intermediate and high strain rates". Chinese Journal of Geotechnical Engineering, 38(6), 2016, pp. 1087-1094.

8. Zhao, H., Wang, Z., Zhang, H., Li, W., "Effects of dynamic loads on development of internal microstructure and distribution of new surface fractures of coal". Chinese Journal of Rock Mechanics and Engineering, 35(5) 2016, pp. 971-979.

9. Li, S., Wang, X., Fan, C., Zhang, H., Liu, Z., Yin, K., "Experimental study on evolution characteristics of coal pores under impact loadings”. China Safety Science Journal, 29 (10), 2019, pp. 91-97.
10. Shu, R., Yin, T., Li, X., Yin, Z., Tang, L., "Effect of thermal treatment on energy dissipation of granite under cyclic impact loading". Transactions of Nonferrous Metals Society of China, 29(2) ,2019, pp. 385-396.

11. Yu, Y., Xu, Q., Diao, X., Yan, Z., "Effect of cyclic impact on sandstone characteristics under confining pressures". Journal of Huazhong University of Science and Technology: Natural Science Edition, 47(6), 2019, pp. 127-132.

12. Wang, T., Song, Z., Yang, J., "Dynamic response characteristics of weathered red sandstone under cyclic impact". Chinese Journal of Rock Mechanics and Engineering, 38(S1), 2019, pp. 2772-2778.

13. Li, S., Zhu, W., Niu, L., Yu, M., "Dynamic characteristics of green sandstone subjected to repetitive impact loading: phenomena and mechanisms". Rock Mechanics and Rock Engineering, 51(6), 2018, pp. 1921-1936.

14. Braunagel, M. J., Griffith, W. A., "The effect of dynamic stress cycling on the compressive strength of rocks". Geophysical Researeh Letters, 46(12), 2019, pp. 6479-6486.

15. Hokka, M., Black, J., Tkalich, D., Fourmeau, M., Kane, A., Hoang, N. H., Li, C., Chen, W., Kuokkala, V. T., "Effects of strainrate and confining pressure on the compressive behavior of Kuru granite". International Journal of Impact Engineering, 91, 2016, pp. 183-193.

16. Lundberg, B., "A split Hopkinson bar study of energy absorption in dynamic rock fragmentation". International Journal of Rock Mechanics and Mining Sciences, 13, 1976, pp. 187-197.

17. Raynaud, S., Fabre, D., Mazerolle, F. Geraud, Y., Latiere, H.J., "Analysis of the internal structure of rocks and characterization of mechanical deformation by a non-destructive method: X-ray tomodensitometry". International Journal of Rock Mechanics and Mining Sciences, 26(6), 1989, pp. 293-294.

18. Kawakata, H., Cho, T., Kiyama, T., Yanagidani, T., Kusunose, K., Shimada, M., "Three-dimensional observations of faulting process in Westerly granite under uniaxial and triaxial conditions by X-ray CT scan”. Tectonophysics, 313(3), 1999, pp. 293-305. 
19. Alam, M. S., Chakraborty, T., Matsagar, V., Rao, K. S., Sharma, p., Singh, M., "Characterization of kota sandstone under different strain rates in uniaxial loading". Geotechnical and Geological Engineering, 33(1), 2015, pp. 143-152

20. Klepaczko, J. R., Hsu, T. R., Bassim, M. N., "Elastic and pseudoviscous properties of coal under quasi-static and impact loadings". Canadian Geotechnical Journal, 21(2), 1984, pp. 203-212.
21. Shalev, E., Lyakhovsky, V., Qugier-simoninaudrey, A., Yariv, H., $\mathrm{Zhu}, \mathrm{W}$., "Inelastic compaction, dilation and hysteresis of sandstones under hydrostatic conditions". Geophysical Journal International, 197 (2), 2014, pp. 920-925. 